20 cases including molecular genetic profiling of 15 tumors. Mod Pathol. 2019;32: 957-66.

3. Dai L, Wanga Z-M, Xue Z-Q, He M, Yuan Y, Shang X-Q, et al. Results of surgical treatment for primary malignant melanoma of the esophagus: a multicenter retrospective study (2019 International Thoracic Oncology Summit \#P5). J Thorac Cardiovasc Surg. 2021;161:294-302.
4. Robert C, Grob JJ, Stroyakovskiy D, Karaszewska B, Hauschild A, Levchenko E, et al. Five-year outcomes with dabrafenib plus trametinib in metastatic melanoma. N Engl J Med. 2019;381:626-36.

5. Larkin J, Chiarion-Sileni V, Gonzalez R, Grob JJ, Rutkowski P, Lao CD, et al. Five-year survival with combined nivolumab and ipilimumab in advanced melanoma. $N$ Engl J Med. 2019;381:1535-46.

\title{
Commentary: All that glitters is not gold
}

\author{
John S. Young, MD, ${ }^{a}$ and M. Blair Marshall, MD ${ }^{\mathrm{a}, \mathrm{b}}$
}

The authors submit results on the surgical treatment for primary melanoma of the esophagus (PMME) to provide new knowledge where little is known. This study collects data from multiple institutions from 1998 to $2018 .{ }^{1}$ Approximately $53 \%$ of patients with PMME were initially misdiagnosed with other types of esophageal cancer. Given the small tissue sample size and poor differentiation, preoperative diagnosis was a challenge. Treatment of all patients followed strategies for esophageal cancer at the time they occurred. Current risk factors such as depth of invasion, subtype, and mutations associated with primary melanoma were not collected but data associated with esophageal cancers were. Positron emission tomography was not in routine use. Forty-one patients $(58.6 \%)$ underwent a Sweet esophagectomy, rarely performed today, $17(24.3 \%)$ a McKeown, $9(12.9 \%)$ an Ivor-Lewis, and $3(4.3 \%)$ a transhiatal. Despite the study reaching 2018, there is no mention of minimally invasive esophagectomy as a surgical approach, even though the companion video is of a minimally invasive esophagectomy. Remarkably, there was no operative mortality and surgical complications, grades II-IV, were low at $19.9 \%$. This is particularly impressive, considering the study spans evolution in perioperative care and surgical techniques dating back to 1998 .

From the a Division of Thoracic Surgery, Brigham and Women's Hospital, Harvard Medical School; and ${ }^{\mathrm{b}}$ Boston VA Medical Center, Boston, Mass.

Disclosures: Authors have nothing to disclose with regard to commercial support.

Received for publication 0,0000 ; revisions received 0,0000 ; accepted for publication March 31, 2020; available ahead of print April 11, 2020.

Address for reprints: John S. Young, MD, Division of Thoracic Surgery, Brigham and Women's Hospital, Harvard Medical School, 75 Francis St, Boston, MA 02115 (E-mail: jyoung0@ partners.org).

J Thorac Cardiovasc Surg 2021;161:304-5

$0022-5223 / \$ 36.00$

Copyright (c) 2020 by The American Association for Thoracic Surgery

https://doi.org/10.1016/j.jtcvs.2020.04.002

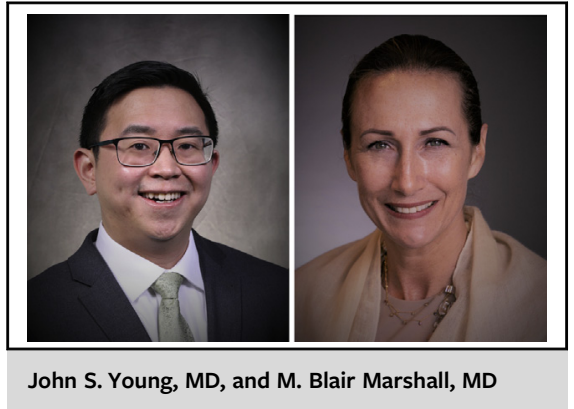

CENTRAL MESSAGE

A retrospective study of patients treated by a variety of strategies is discussed. With recent knowledge gained in melanoma, the risk factors and optimal treatment strategies remain to be defined.

Sex, presence of lymph node metastasis, extent of lymph node dissection, and postoperative therapy are reported as independent factors affecting prognosis. Although a more extensive lymph node dissection was associated with improved survival, it was not statistically significant. The impact of lymphadenectomy is a current point of controversy in patients with primary melanoma. Two randomized prospective studies have demonstrated no 10-year survival benefit in sentinel node positive patients undergoing lymphadenectomy. ${ }^{2,3}$ In the current study, those patients who received adjuvant treatment from a variety of regimens also had improved survival, although few had initial therapy specific to melanoma, and even fewer had radiation therapy. Today, therapy for melanoma is rapidly evolving, with the introduction of several targeted therapies that have demonstrated significant improvement in survival even in late staged patients. ${ }^{4}$ 
This paper serves to remind us of a time when the approach to PMME was based on our evolving knowledge of cancer of the esophagus, a reflection of the era in which these patients were treated. Routine use of immunohistochemistry in esophageal cancers characterized as poorly differentiated will likely increase diagnostic accuracy. This will have a critical impact on the outcomes in these patients. Once the diagnosis of melanoma of the esophagus is made, these patients will undergo staging, including positron emission tomography scanning and molecular testing, and be treated with immunotherapy or other targeted therapy when applicable along with likely an esophagectomy at some point. Clinical decision making defining the optimal treatment strategy will be patient specific based on sourced opinion from multiple experts, including thoracic surgeons armed with specific knowledge relevant to melanoma. The authors should be commended for their efforts to provide clarity where there is none and for presenting the largest series to date of an extremely rare disease. The insights gleamed from their work in this area will likely improve the care of patients with PMME.

\section{References}

1. Dai L, Wang Z-M, Xue Z-Q, He M, Yuan Y, Shang X-Q, et al. Results of surgical treatment for primary malignant melanoma of the esophagus: a multicenter retrospective study (2019 International Thoracic Oncology Summit \#P5). J Thorac Cardiovasc Surg. 2021;161:294-302.

2. Morton DL, Thompson JF, Cochran AJ, Mozzillo N, Nieweg OE, Roses DF, et al; MSLT Group. Final trial report of sentinel-node biopsy versus nodal observation in melanoma. N Engl J Med. 2014;370:599-609.

3. Faries MB, Thompson JF, Cochran AJ, Andtbacka RH, Mozzillo N, Zager JS, et al Completion dissection or observation for sentinel-node metastasis in melanoma. $N$ Engl J Med. 2017;376:2211-2.

4. da Silveira Nogueira Lima JP, Georgieva M, Haaland B, de Lima Lopes G. A sys tematic review and network meta-analysis of immunotherapy and targeted therapy for advanced melanoma. Cancer Med. 2017;6:1143-53. 